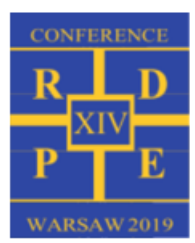

\title{
Evaluation of long-term start up costs impact on short-term price based operational optimization of a CCGT using MILP
}

\author{
Sylwia Gotzman ${ }^{1,}{ }^{,}$, Paweł Ziółkowski ${ }^{2}$,Janusz Badur ${ }^{1}$ \\ ${ }^{1}$ Szewalski Institute of Fluid-Flow M achinery, Polish A cademy of Sciences, Fiszera 14, 80-231 Gdańsk, ${ }^{*}$ corresponding author \\ sylwia.gotzman@imp.gda.pl, jb@imp.gda.pl, Poland \\ 2 Gdansk University of Technology, Faculty of Mechanical Engineering, Narutowicza 11/12, 80-233 Gdańsk, e-mail: \\ pawel.ziolkowski1@ pg.edu.pl, Poland
}

\begin{abstract}
A $n$ increasing share of the weather-dependent RES generation in the power system leads to the growing importance of flexibility of conventional power plants. They were usually designed for base load operation and it is a challenge to determine the actual long-term cycling costs, which account for an increase in maintenance and overhaul expenditures, increased forced outage rates and shortened life expectancy of the plant and components. In this paper, the overall impact of start up costs is evaluated by formulating and solving price based unit commitment problem (PBUC). The electricity spot market is considered as a measure for remunerating flexibility. This approach is applied to a real-life case study based on the 70 MWe PGE Gorzów CCGT power plant. Different operation modes are calculated and results are used to derive a mixed integer linear programming (MILP) model to optimize the operation of the plant. The developed mathematical model is implemented in Python within the frame of the PuLP library and solved using GUROBI. Results of the application of the method to a numerical example are presented.
\end{abstract}

\section{Introduction}

The installed capacity growth of fluctuating renewable sources puts a strain on the remaining dispatchable power plants. Namely, the volatile character of the residual load forces conventional power plants to meet ever higher flexibility requirements, as more frequent start-ups and shut-downs, part-load operation and consequently falling operating hours are required from them. This effect can al ready be seen in the present and is expected to increase in the future. According to [1], as many as 200 start-ups and as few as 1500-4500 operating hours per year should be the target flexibility parameters of conventional power plants.

From the perspective of the Transmission System Operator (TSO), flexible power plants help ensure the stability of the power system. From the perspective of a power plant operator, enhancing the flexibility parameters results in a higher profitability of the power plant. As deregulation and an increasing share of volatile generation leads to more variability in electricity prices on the spot market [2], price signals give incentives for cyclic operation of power plants. If a power plant may follow daily, weekly and annual market trends, it may avoid electricity production when spot prices drop below marginal costs, and on the other hand, maximize electricity production in the high spread periods.

The last two decades have witnessed a growing interest in gas fueled power plants across Poland. These are usually combined cycle gas turbines (CCGTs). The total installed capacity of CCGTs in Poland today is around $2 \mathrm{GW}$ and should approach $3 \mathrm{GW}$ by 2020 , when
EC Stalowa Wola and EC Żerań power plants start operating [1]. CCGTs are much more capable of providing sufficient flexibility to the power system compared to coal-fired units, which today account for $70 \%$ of total installed capacity in Poland [3]. $\mathrm{N}$ evertheless, these plants are usually built for base-load operation, which means they do incur high costs when operated cyclically. The subject of actual costs of cycling is not entirely obvious. Besides direct costs (mainly fuel costs during the start-up), power plant cycling entails long-term costs, like increased maintenance and repair expenditures, costs of unplanned outages and component life expectancy shortening. The long-term costs occur in the future and often can only be predicted with a degree of uncertainty. Consequently, they are prone to being underestimated. A s the authors of [4] point out, the long-term costs often exceed the shortterm profits if not taken into consideration when submitting a bid price. Therefore, it is essential to have a good understanding of the actual costs of cycling the plant and use the insights to determine how to respond to the time-sensitive electricity prices when making shortterm scheduling decisions.

For this purpose, we address the issue of an optimal CCGT plant operation schedule according to 2019 Polish electricity spot market prices. Typical flexibility constraints to thermal generation units include start-up costs, minimum/maximum generation limits, ramping costs and ramp rates. As neither the heat demand constraints nor the TSO requirements are taken into consideration, ramping parameters are not included in the analysis. We derive a mixed integer linear 
programming (MILP) model of unit commitment (UC) with rolling horizon and implement it in PuLP Python. Then, PGE Gorzów power plant is analyzed and the model is run over a range of different flexibility parameters to evaluate the impact of start-up costs on optimal scheduling decisions.

\section{Literature review}

In the literature, the problem of scheduling of generation units over a daily or weekly time horizon in order to accomplish some objective while meeting some physical and operational constraints, vary considerably in size and scope. Consequently, there is no uniform terminology. W e decided to stick to the term "unit commitment" as it is specific to the energy sector as opposed to "scheduling" and as it is more commonly used by solution techniques researches than "economic dispatch". The meaning of the term "unit commitment" is ambiguous [5]. There are authors using the term "unit commitment" in a narrow sense, where it refers to the on/off status of generators and then economic dispatch is performed to specify the generation level of the units [e.g. 6-9]. In a broad sense, as it is used in this paper, UC refers to determining both the on/off status and the generation level. At the power plant or one owner level, this problem is also called self commitment [e.g. 10], self-scheduling problem [e.g. 11] or simply scheduling problem [e.g.12].

Under the traditional regulated monopoly paradigm, unit commitment model seeks to determine the optimum operating point of the available generation units in order to satisfy the forecasted level of demand with the minimum operating cost. In a competitive setting, electricity and reserve prices are important factors in the decision process for unit commitment scheduling. Power plants have freedom to schedule their generators to produce less electricity than predicted load in order to maximize their profit. In the literature the problem is called the profit based unit commitment problem (PBUCP) [e.g. 13].

There are many different modeling approaches to the unit commitment problem. In many cases they were applied to combined cycle power plants [e.g. 5, 8, 10, 12, $14,15]$. Models proposed to simulate thermal unit operations differ considerably in the degree of detail. The least technologically detailed unit commitment models consider the units at a plant level, which means that the interactions of components within the plant are not modeled [e.g. 16]. M ore realistic models in terms of modeling operation of a CCGT accurately can be achieved either through introducing different power plant operation modes (configurations) [e.g. 14] or base the model on physical components [e.g. 12]. In the current work, we implemented the operation modes based model.

In the case of real-life case studies, typically in the first step the power plant is modeled [e.g. 8]. For components not included in the standard library, programmable components are used. After a validation of the plant model, an optimization tool is implemented in some numerical computing environment and simulations are run based on the plant technical data and technical and economic assumptions.

There has also been a proliferation of research on solution techniques for the unit commitment problem due to its complexity and practical importance. The most common solution techniques include MILP, dynamic programming (DP), Lagrange relaxation and prioritylist. Readers can refer to [17] for a comprehensive overview of different methods. The solution approach that has become very popular is M ixed-Integer Linear Programming (MILP) approach due to significant improvements in off-the-shelf MILP solvers, based on the branch-and-cut algorithm [18].

\section{Model formulation}

\section{Objective function}

The objective function of the optimization states the profit from the operation, which shall be maximized. Revenues originate from selling the electricity on the wholesale market. The costs included in the model are composed of variable and fixed costs and will be discussed later in this section. The objective function is formulated as follows:

$$
\left.\sum_{t=0}^{T} \sum_{m=0}^{M} \begin{array}{c}
\left(s_{t, m} * P^{\text {Futures }} * c^{\text {Futures }}\right)+ \\
+\left(P_{t}^{\text {Spot }} * c_{t}^{\text {Spot }}\right)+ \\
-\left(P_{t}^{\text {Generation }} * \text { varCost }_{m}\right)+ \\
-\left(s_{t, m} *\right. \text { fixCost } \\
m
\end{array}\right)+
$$

where $T$ is the time horizon with a time step of one hour indexed with $t ; m$ and $M$ are an operation mode index and the number of operation modes respectively; $P$ is the amount of electricity in MWh; $c$ is the price of electricity in PLN/M Wh, varCost $_{m}$ is the variable unit cost of electricity generation for operation mode $m$ in PLN/MWh, fixCost ${ }_{m}$ are the fixed costs of electricity generation for operating mode $m$ and as such are expressed in PLN per hour; $s_{t, m}$ is a status (binary) variable indicating which mode $m$ is the plant on at hour $t$. The following constraint ensures that only one operation mode at a time is selected:

$$
\sum_{m=0}^{M} s_{t, m}=1
$$

W e assumed that a constant amount of electricity for each hour of the analyzed period has been sold on the futures market at a constant price and the remaining output can be sold on the spot market. Also buying electricity on the spot market is made possible in order to avoid electricity generation when prices drop below marginal costs. $P_{t}^{\text {Generation }}$ is the amount of electricity generated during hour $t, P^{\text {Futures }}$ is the amount of electricity sold on the futures market and it is constant throughtout the whole period, and $P_{t}^{\text {Spot }}$ is the electricity sold $(>0)$ or bought $(<0)$ on the spot market so that at each hour:

$$
P^{\text {Futures }}+P_{t}^{\text {Spot }}=P_{t}^{\text {Generation }}
$$




\section{Technical constraints}

A typical combined cycle gas fueled plant consist of one or more gas turbine generators (GT), each one of them with its own heat recovery steam generator (HRSG), and one conventional steam turbine generator (ST). Lager CCGT plants frequently generate steam at multiple pressure levels, so that STs include dual or triple pressure sections in order to operate at a higher thermal efficiency level. The more components the system has, the larger number of possible operation modes (configurations of the components) should be taken into consideration to allow accurate optimization of the plant scheduling. In our model there are 6 operation modes:

1) off $(O F F)$,

2) cold start-up (coldSU),

3) warm start-up (warmSU),

4) minimum complaint load operation $(M C L)$,

5) part-load operation (PART),

6) nominal load operation (NOM).

The generation capacity, overall efficiency of the plant and $\mathrm{CO}_{2}$ emissions change depending on the operation mode. They all are modeled as constant values characterizing each operation mode. Better accuracy of the model can be achieved through higher resolution of operation modes.

For each mode, a feasible operation area is defined by its minimum and maximum electricity generation. A continuous operation range between the minimum and maximum el ectricity generation can be formulated using the binary operating variable as:

$$
\sum_{m=0}^{M} s_{t, m} * P_{m}^{\min } \leq P_{t}^{\text {Generation }} \leq \sum_{m=0}^{M} s_{t, m} * P_{m}^{\max }
$$

where $P_{m}^{\min }$ and $P_{m}^{\max }$ are the minimum and maximum electricity generation at mode $m$ respectively.

These are all the technical constraints of the optimization problem. Constraints forcing the optimum to lay in the part-load operation area (e.g. heat demand or TSO constraints) are not considered in this model. Also, due to the hourly resolution of the model, ramping between different load points is considered fast and thus not included in the modeling.

\section{Start-up modes}

In order to reflect the higher cost of starting up a cold power plant, two start-up modes are introduced: cold start-up mode and warm start-up mode. Both the cold and the warm start-up modes are represented by hourly operation modes in the same manner as the offline mode or the different generation modes. Start-up duration is not taken into consideration, as the optimal offline time proceeding start-ups is long enough to assume the process had been initialized sufficiently in advance.

A start-up in the hour before normal operation can be forced by the following logical constraints:

$$
-s_{t-1, \text { OFF }}+s_{t, \text { OFF }}+s_{t, \text { cold } S U}+s_{t, \text { warm } S U} \geq 0
$$

Selection of the correct start-up type of the plant, depending on the prior offline time, is achieved by adding another inequality constraining the warm start-up status variable $s_{t, \text { warmsu }}$ to be zero at hour $t$ unless the offline time prior to that hour was shorter or equal to $L$ hours:

$$
\text { offTime }_{t}-L \leq 1000 *\left(1-s_{t, \text { warmsu }}\right)
$$

where off Time $_{t}$ denotes the number of offline hours within the period of length $L$ preceding the hour $t$.

\section{Production costs}

We focus on the short run costs of electricity generation and capital expenditures do not appear in our model. It is common to divide generation costs into two categories: fixed costs, which are the costs independent of the power plant output, and variable costs that do vary with the power plant output. The fixed production costs consist of fixed O\&M costs, labour costs, external services, and other general costs which do not vary with the output of the power plant. The variable production costs in our model consist of the expenses for fuel and $\mathrm{CO}_{2}$ allowances and variable operations and maintenance $(O \& M)$ costs. We assumed that the expenses for fuel and $\mathrm{CO}_{2}$ allowances differ depending on the operation mode, but the variable $0 \& M$ costs are constant per $1 \mathrm{MWh}$ of generated electricity and are common for all the operation modes. The variable $O \& M$ costs and fixed costs are strongly dependent on cyclicality of operation $[19$, p. 599]. In the model they should be set at a level appropriate for base-load operation, as any increase in the production costs due to start-ups, especially in the O\&M costs, should be reflected in the start-up costs.

In the literature production costs are usually formulated via quadratic [e.g. 16] or cubic [e.g. 15] functions, which are further linearized into piecewise linear forms. The slope of each segment is then used in the objective function as it represents the incremental cost of a given generation range. In our optimization model production costs are represented by a step function, so that the marginal and average variable costs are constant for a given generation range. In particular, the heat rate is constant for a given operation mode.

\section{Start-up costs}

It is a broadly accepted approach in the literature to refer to the start-up costs as the transition costs between different operation modes. In our formulation of the problem the start-up costs are assigned to the start-up modes as their fixed costs, as they do not depend on the operation mode following the start-up mode.

Start-up costs are composed of [20]:

- costs of additional fuel due to heat rate losses during start-up; auxiliary power usage, chemicals and additional manpower required during start-up;

- depreciation of the components exposed to wearing and additional fuel due to heat rate losses stemming from the wear of the equipment; increased maintenance, repair and overhaul expenditures; increased forced outages; critical equipment life shortening. 
The former are direct costs and are easily accounted for. The latter occur in the future and a great part of them can only be predicted with a degree of uncertainty.

\section{Case study}

\section{Technical characteristics of the plant}

The proposed formulation has been applied to solve a unit commitment problem for Gorzów CCGT plant, the first CCGT plant in Poland. The plant consists of one gas turbine of $55 \mathrm{MWe}$, one heat recovery steam generator (HRSG) and two steam-turbines of 5 and $6 \mathrm{MWe}$ respectively. The layout of the plant is presented in Figure 1.

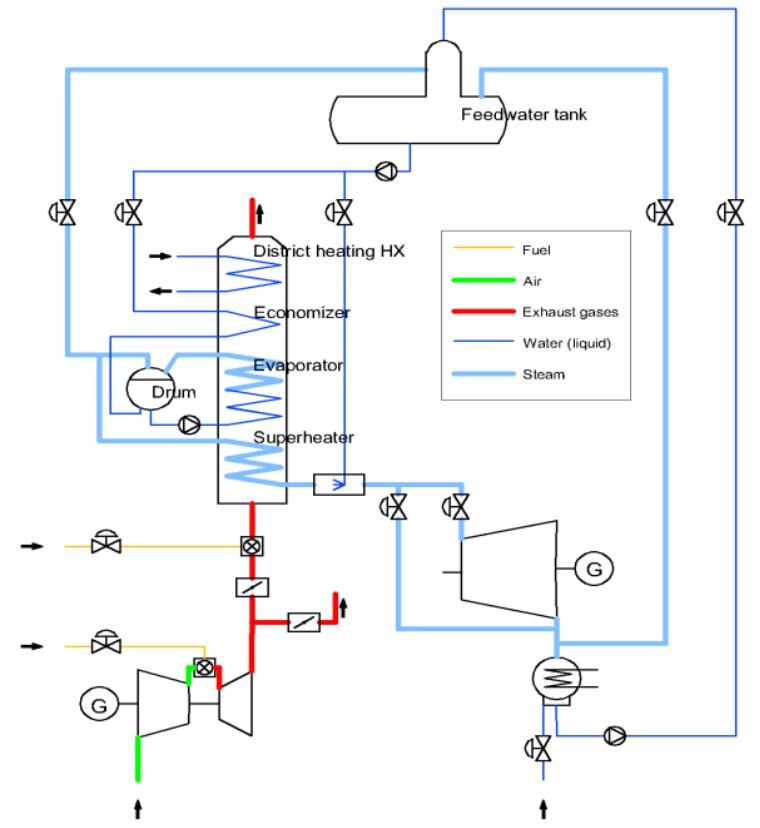

Fig. 1. The layout of the Gorzów CCGT plant.

A detailed thermodynamic cycle analysis of the steady-state design operating point of the system was conducted using an in-house code COM-GAS in [21]. The electrical efficiencies at the nominal load of the GT and of the two STs together were estimated at 34\% and $15 \%$ respectively. However, the overall electrical efficiency of the CCGT power plant was estimated to be $41 \%$. The overall efficiencies of the plant at $M C L$ and PART operation modes were estimated according to data from [22]. Historical data were used to estimate the overall efficiencies of the plant at coldSU and warmSU operation modes and the $\mathrm{CO}_{2}$ specific emission factor. The output at $M C L$ was assumed to be $50 \%$ of the nominal GT output - the upper bound for one GT systems according to [23]. The maximum number of offline hours preceding the warm start-up mode is assumed at 30 .

\section{Costs and market assumptions}

The assumptions about costs are based on the literature (Table 1). Market data assumptions are based on TGE data (T able 2). It is assumed that $1 €=4.3$ PLN.
Table 1. Costs assumptions

\begin{tabular}{l|c|c} 
& Value & Source \\
\hline Variable O\&M costs & $2.4 € / \mathrm{MWh}$ & {$[24]$} \\
$\begin{array}{l}\text { Fixed costs } \\
\text { Warm start-up }\end{array}$ & $15 \mathrm{k} € / \mathrm{MW} / \mathrm{y}$ & {$[20]$} \\
$\begin{array}{l}\text { reference scenario costs } \\
\text { Cold start-up } \\
\text { reference scenario costs }\end{array}$ & $2 \times 51.0 € / \mathrm{MW}$ capacity & {$[25]$} \\
& $2 \times 73.2 € / \mathrm{MW}$ capacity & {$[25]$}
\end{tabular}

Table 2. M arket data assumptions

\begin{tabular}{l|c} 
& Value \\
\hline Electricity spot prices & TGE DAM prices, first fixing \\
Electricity futures price & $250 \mathrm{PLN} / \mathrm{M} \mathrm{Wh}$ \\
CO2 emission allowance & $20 € / \mathrm{tCO}_{2}$ \\
cost & $70 \mathrm{PL} \mathrm{N} / \mathrm{M} \mathrm{Wh}$ \\
Fuel price &
\end{tabular}

A scheduling problem is solved on a 4380 hour time horizon based on historical TGE day ahead market (DA M ) electricity prices of the first half of the year 2019 (Figure 2). A rolling horizon method as described in [26] is used, i.e. the overall result is gained by optimizing successive $48 \mathrm{~h}$ planning intervals, each shifted $24 \mathrm{~h}$ forward, and concatenating the results.

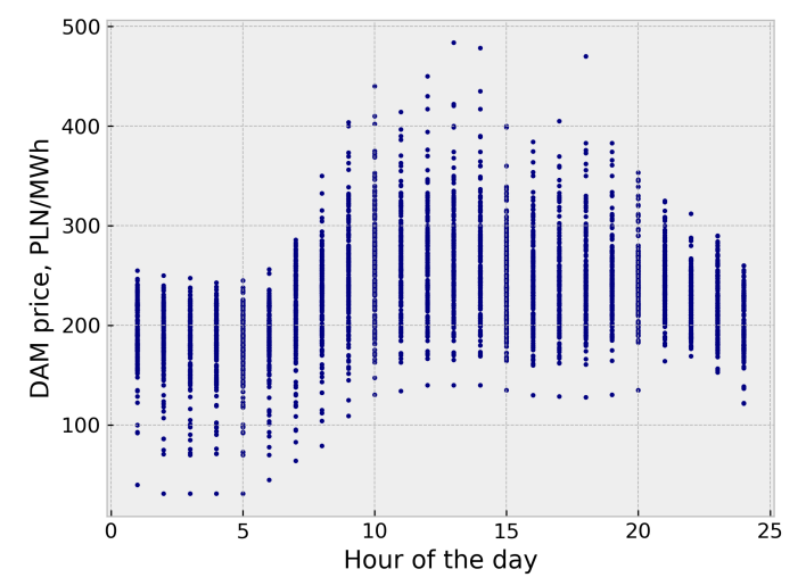

Fig. 2. TGE DAM prices in the first half of 2019.

\section{Results and discussion}

Four case study scenarios are provided to demonstrate the impact of start-up costs on optimal scheduling of the plant, in particular on the number of start-ups.

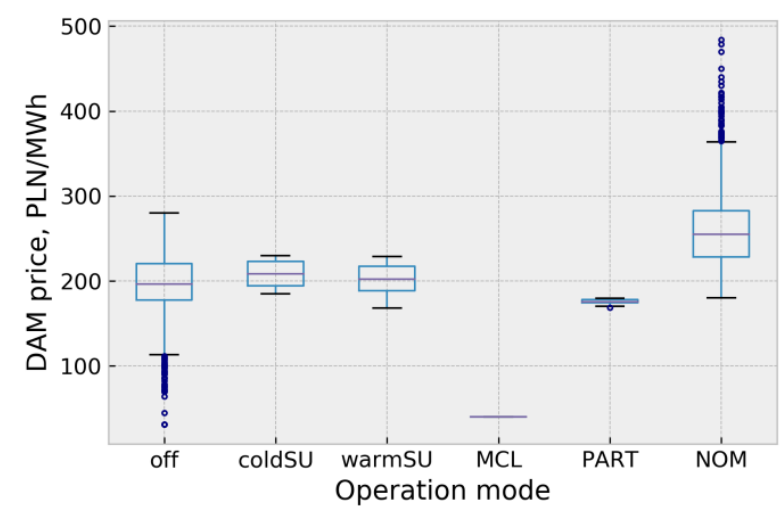

Fig. 3. Distribution of TGE DAM electricity prices at each operation mode for the reference scenario. 
Figure 3 shows data on TGE DAM 2019 prices grouped into operation modes that resulted from solving the UC problem for the reference scenario (\#0). The optimal number of start-ups within the time horizon amounts to 24 (12 cold and 12 warm, see Figure 4 and Table 3), which is circa one start-up a week.

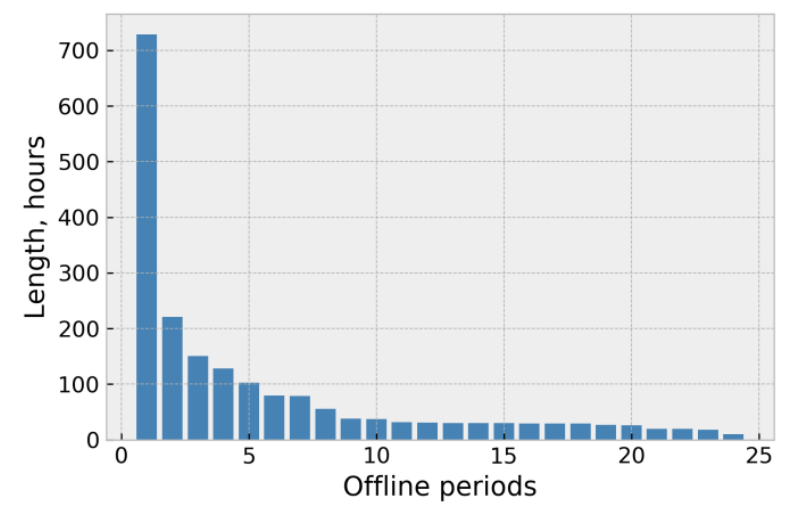

Fig. 4. Offline periods and their length for scenario \#0.

Scenario \#0 uses all the assumptions described in the Case study section. In particular, the start-up costs are twice higher than what are the best case assumptions according to [25], the maximum number of offline hours preceding the warmSU mode is 30 and the maximum output at MCL is $50 \%$ of the nominal GT output. In the scenarios \#1, \#2 and \#3 we lift the assumptions one at a time.

Table 3. Counts of each operation mode hours

\begin{tabular}{l|cccccc} 
& off & $\begin{array}{c}\text { cold } \\
\text { SU }\end{array}$ & $\begin{array}{c}\text { warm } \\
\text { SU* }\end{array}$ & MCL & PART & NOM \\
\hline Scenario \#0 & 1983 & $\mathbf{1 2}$ & $\mathbf{1 2}$ & 1 & 22 & 2338 \\
Scenario \#1 & 1808 & $\mathbf{2 3}$ & $\mathbf{3 3}$ & 1 & 1 & 2526 \\
Scenario \#2 & 2030 & $\mathbf{8}$ & $\mathbf{1 6}$ & 1 & 18 & 2319 \\
Scenario \#3 & 1760 & $\mathbf{1 9}$ & $\mathbf{3 2}$ & 76 & 0 & 2505
\end{tabular}

* The meaning of the number of hours is the number of start-ups.

Scenario \#1 assumes the best case start-up costs from [25], which are 51 and $73 €$ per $1 \mathrm{MW}$ of capacity for warm and cold start-up respectively. If the plant operator underestimated the start-up costs, they would schedule the generation according to scenario \#1 while incurring costs of scenario \#0. As a result, there would be 23 cold start-ups and 33 warm start-ups throughout the whole time horizon of 26 weeks (Table 3, Figure 5), i.e. more than 2 start-ups a week. The profit seems to have increased by almost PLN 0.6 million (Table 4), but that is roughly the same amount as the overlooked difference in the overall costs of start-ups. It should be noted, though, that the number of start-ups with a prior offline period of no more than 8 hours has increased from 0 in scenario \#0 to 12 in scenario \#1 (Table 4), which means the start-up costs would have been lower, had we taken in consideration so called hot start-ups in the model.

In scenarios \#2 and \#3 we aim at estimating the revenues gained from flexibilization of the power plant, as they provide a target framework for possible investment costs. We want to answer the question: Can flexibility retrofitting costs be justified by the resultant reduction in cycling costs?
Table 4. The value of the objective function and the number and length of offline periods

\begin{tabular}{|c|c|c|c|c|}
\hline & \multirow{2}{*}{$\begin{array}{c}\text { Profit } \\
\text { [PLN } \\
\text { / half a year] }\end{array}$} & \multicolumn{3}{|c|}{ Number or offline periods } \\
\hline & & Total & $\begin{array}{c}\leq 8 \mathrm{~h} \\
\text { (hot start- } \\
\text { ups) }\end{array}$ & $\begin{array}{c}>48 \mathrm{~h} \\
\text { (very cold } \\
\text { start-ups) }\end{array}$ \\
\hline Scenario \#0 & 5338789 & 24 & 0 & 8 \\
\hline Scenario \#1 & 5932543 & 56 & 12 & 14 \\
\hline Scenario \#2 & 5450843 & 24 & 0 & 8 \\
\hline Scenario \#3 & 5956448 & 51 & 8 & 14 \\
\hline
\end{tabular}

In scenario \#2 the maximum number of offline hours preceding the warm-start up mode is increased from the reference $30 \mathrm{~h}$ to $48 \mathrm{~h}$, which could be achieved by keeping the components hot. The optimization results show an increase in the plant's profit of $112 \mathrm{k}$ PLN (Table 4), which translates to about $0.8 € / \mathrm{kW} / \mathrm{y}$. That certainly does not justify the investment costs required for flexibility retrofitting, which are roughly estimated to be 100 to $500 € / \mathrm{kW}$ [28].

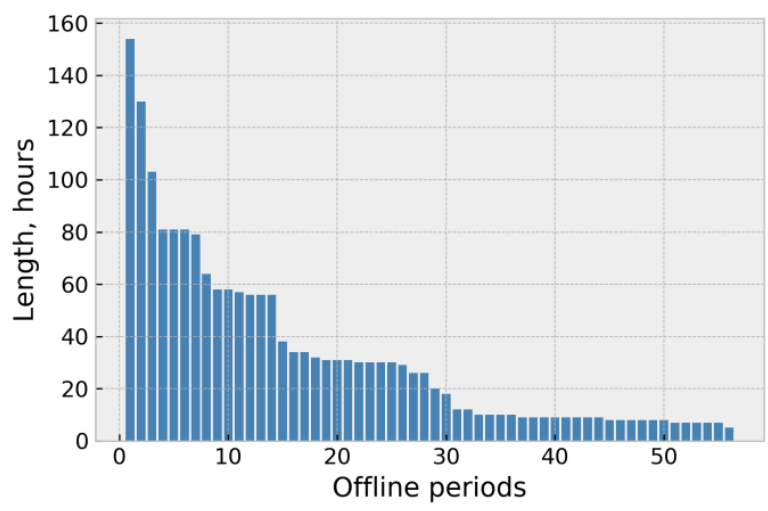

Fig. 5. Offline periods and their length for scenario \#1.

In scenario \#3 the maximum output at $\mathrm{MCL}$ is decreased from the reference $50 \%$ to $25 \%$ of the nominal GT output, so that the cost of staying online at minimum load is lowered. This flexibility improvement results in PLN 0.6 million higher profit in the optimized period (Table 4), which gives quite a significant amount of 1.2 million PLN/y. It is worth noting that lowering the minimum load - considered a measure to avoid cycling costs [4] - caused more frequent shut-downs and startups.

\section{Conclusions and perspectives}

In the paper we developed an optimizing tool for electricity generation scheduling and applied it to Gorzów CCGT plant data and historical DAM prices of the first half of 2019. The impact of underestimated start-up costs and flexibility improvements on operation of the power plant and the financial results were presented.

In future work we would like to investigate a case of a CCGT with an energy storage and a case of a CCGT with heat demand constraints. We expect the former to be very sensitive to misjudged long-term start-up costs and the latter to benefit much more than it was showed in this paper from improving flexibility parameters. 


\section{Acknowledgements}

The authors would like to thank PGE Energia Ciepła SA Gorzów Wielkopolski Subsidiary for providing necessary data.

\section{References}

1. Bronk L., Czarnecki B., Magulski R., Elastyczność krajowego systemu elektroenergetycznego, Raport Forum Energii, (2019).

2. Green R., V asilakos N. M arket behaviour with large amounts of intermittent generation, Energy Policy 38(7):3211-3220, (2010).

3. Macuk R., Maćkowiak-Pandera J., GawlikowskaFyk A., Rubczyński A., Transformacja energetyczna $w$ Polsce, Raport Forum Energii, (2019).

4. Lefton S. A., Hilleman D., M ake Y our Plant Ready for Cycling Operations, Intertek-A ptech, www.powermag.com, (2011).

5. Dai H., Zhang N., Su W, A Literature Review of Stochastic Programming and Unit Commitment, Journal of Power and Energy Engineering, Vol. 3, pp. 206-214, (2015).

6. Biggar D., Hesamzadeh R., The Economics of Electricity Markets, John Wiley \& Sons Ltd., (2014).

7. Arabas J., Mościcki M., Świrski K., Rozszerzenie zadania ekonomicznego rozdziału obciążeń w warunkach rynku energii, Transition Technologies SA, www.cire.pl, (2001).

8. Angerer M., Djukow M., Riedl K., Gleis S., Hartmut $\mathrm{S}$, Simulation of Cogeneration-Combined Cycle Plant Flexibilization by Thermochemical Energy Storage, Journal of Energy Resources Technology, Vol. 140(2), (2017).

9. Rist J., Dias M., Palman M., Zelazo D., Cukurel B., Economic dispatch of a single micro-gas turbine under CHP operation, Applied Energy, Vol. 200, pp. 1-18, (2017).

10. Papavasiliou A., He Y., Svoboda A., SelfCommitment of Combined Cycle Units Under Electricity Price Uncertainty. IEEE Transactions on Power Systems, V ol. 30, pp. 1690-1701, (2015).

11. Simoglou C., Biskas P., Bakirtzis A., Optimal SelfScheduling of a Thermal Producer in Short-Term Electricity M arkets by M ILP, IEEE Transactions on Power Systems, V ol. 25, pp. 1965-1977, (2010).

12. M itra, S., Sun L., G rossmann I., O ptimal Scheduling of Industrial Combined Heat and Power Plants under Time-Sensitive Electricity Prices, Energy, Vol. 54, pp. 194-211. (2012)

13. Li, T., Shahidehpour, M., Price-Based Unit Commitment: A Case of Lagrangian Relaxation Versus Mixed Integer Programming. Power Systems, IEEE Transactions on Power Systems, V ol. 20, pp. 2015-2025, (2005).

14. López J., Gómez R., Guillén I., Practical commitment of combined cycle plants using dynamic programming. Proceedings of the 2010 Electrical Power and Energy Conference, (2010).
15. Alemany J., Moitre D., Pinto H., Magnago F., ShortTerm Scheduling of Combined Cycle Units Using Mixed Integer Linear Programming Solution, Energy and Power Engineering, Vol. 5, pp. 161170, (2013).

16. Carrion M., Arroyo J. M., A Computationally Efficient Mixed-Integer Linear Formulation for the Thermal Unit Commitment Problem, IEEE Transactions on Power Systems, Vol. 21(3), (2006).

17. A ckooij W., Lopez I., Frangioni A., Lacalandra F., Tahanan M., Large-scale unit commitment under uncertainty: an updated literature survey, Annals of Operations Research, Springer, V ol. 271(1), pp. 1185, (2018).

18. Morales-España G., Latorre J., Ramos A., Tight and Compact MILP Formulation for the Thermal Unit Commitment Problem, IEEE Transactions on Power Systems, Vol. 28(4), (2013)..

19. Gülen S., Gas Turbines for Electric Power Generation, Cambridge University Press, (2019).

20. Schröder A., Kunz F., Meiss J., Mendelevitch R., von Hirschhausen C., Current and Prospective Costs of Electricity Generation until 2050, DIW Data Documentation, No. 68, Deutsches Institut für Wirtschaftsforschung (DIW), Berlin, (2013).

21. Ziółkowski P., Lemański M., Badur J., Nastałek L., Power augmentation of PGE Gorzow's gas turbine by steam injection - thermodynamic overview. Rynek Energii, V ol. 98, pp. 161-167, (2012).

22. Kehlhofer R., Rukes B., Hannemann F., Stirnimann F., Combined-Cycle Gas \& Steam Turbine Power Plants, PennWell Books (2009)..

23. Chmielniak T., Lepszy S., Czaja D., Economic assessment of gas-steam systems taking account of variable loads, Journal of Power of Technologies, Vol. 95, pp. 54-62, (2015).

24. Mikołajuk H., Duda M., Radović U., Skwierz S., Lewarski M., Kowal I., Aktualizacja analizy porównawczej kosztów wytwarzania energii elektrycznej w elektrowniach jądrowych, węglowych i gazowych oraz odnawialnych źródłach energii, Agencja Rynku Energii, Warszawa, (2016).

25. Prina M., Fanali L., Manzolini G., Moser D., Sparber W., Incorporating combined cycle gas turbine flexibility constraints and additional costs into the EPLANopt model: The Italian case study, Energy, Vol. 160, pp. 33-43, (2018).

26. Prina M., Fanali L., Manzolini G., Moser D., Sparber W., Incorporating combined cycle gas turbine flexibility constraints and additional costs into the EPLANopt model: The Italian case study, Energy, Vol. 160, pp. 33-43, (2018).

27. Marquant J., Evins R., Carmeliet J., Reducing Computation Time with a Rolling Horizon Approach Applied to a MILP Formulation of Multiple Urban Energy Hub System, Procedia Computer Science, Vol. 51, pp. 2137-2146, (2015).

28. Agora Energiewende, Flexibility in thermal power plants - With a focus on existing coal-fired power plants, (2017). 